\title{
Les traduccions al català de Marguerite Yourcenar: edicions i recepció crítica
}

\author{
Luisa COTONER CERDÓ \\ Centre d'Estudis Interdisciplinaris de les Dones \\ Grup de recerca Estudis de gènere: traducció, literatura, història i comunicació \\ Universitat de Vic \\ mluisa.cotoner@uvic.cat
}

\begin{abstract}
RESUM
Dins el marc d'un projecte més ampli que vol abastar l'anàlisi de les traduccions d'obres literàries escrites per dones, l'objectiu d'aquest article és establir l'estat de la qüestió de les traduccions al català de l'obra de Marguerite Yourcenar i oferir una primera aproximació a la recepció crítica que aquestes traduccions han tingut a la premsa catalana. Per això hem ordenat l'estudi en tres apartats: $a$ ) cronologia de les traduccions de Yourcenar al català; $b$ ) referències bibliogràfiques de les obres de Marguerite Yourcenar traduïdes al català i/o al castellà; $c$ ) recepció de les traduccions catalanes de Yourcenar a la premsa de Catalunya.
\end{abstract}

Paraules clau: història de les traduccions al català; gènere i literatura; Marguerite Yourcenar

[Recibido, enero 2011; aprobado, mayo 2011]

\section{Marguerite Yourcenar's translations into Catalan: editions and critical reception}

\begin{abstract}
As part of a larger project that is directed to the analysis of translations of literary works written by women, the aim of this paper is to establish the state of the art of translation into Catalan of Marguerite Yourcenar's work and to provide a first approximation to the criticism of the translations in the Catalan press. So we ordered the study in three parts: a) the timing of Yourcenar's Catalan translations b) references to the works of Marguerite Yourcenar translated into Catalan and / or Spanish c) reception of Yourcenar's Catalan translations of the Catalan press.
\end{abstract}

Keywords: history of translation into Catalan, gender and literature, Marguerite Yourcenar 
L'objectiu d'aquest article és establir l'estat de la qüestió de les traduccions al català de Marguerite Yourcenar i oferir una primera aproximació a la recepció dins la premsa catalana.

\section{Antecedents}

L'estudi del professor René Garguilo (1989), "Marguerite Yourcenar et l'Espagne", on enumera els nombrosos viatges que Yourcenar va fer a la Península (Sevilla, Madrid, Burgos, León, Cadis, Còrdova, Granada, ${ }^{1}$ Santiago de Compostela, Astúries, Toledo, Canàries...), no fa cap referència a una possible estada de l'escriptora al Principat. Tampoc no hi destaca cap relació amb Catalunya en referir-se a la vinculació d'alguns dels personatges de Yourcenar amb les terres i la cultura espanyola, l'emperador Adrià sense haver d'anar més lluny, la infància espanyola del qual és un tema important al començament de les seves Memòries, o la pintura del Greco, que inspirà el relat " $D$ 'après Gré-

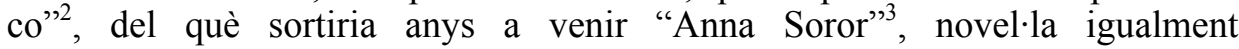
d'inspiració espanyola (Garguilo, 1989: 64-68). Això no obstant, el periodista Ignasi Aragay a l'article "Joan Triadú fa memòria" afirma que el gran assagista i crític literari:

Va ensenyar Barcelona a Marguerite Yourcenar en una breu visita que hi va fer l'any 1964. Tot i que l'escriptora no entenia gaire això del català, va quedar impressionada per la collecció Bernat Metge de clàssics grecs i llatins traduïts. Després van mantenir el contacte. (Aragay, 2008: 34)

Segons explica Michéle Goslar (2002), un altre detall relacionat amb Catalunya és que Yourcenar va conèixer Émile Noulet i Josep Carner cap a 1954 o 1955 als cercles literaris belgues. La referència, però, és molt breu: "conocí a Émile Noulet, exegeta de Valery, Mallarmé y Rimbaud, y a su marido Josep Carner, importante poeta catalán y diplomático en México" (Goslar, 2002: 217). No gaire cosa, doncs, al cap d'avall. Potser, però, tampoc Catalunya era de bon principi gaire yourcenariana, com es pot deduir de l'article de Claude Benoit, on constata referint-se a Mémoires d'Hadrien (1951) que: "la traduction catalane est tardive par rapport à celles des langues voisines" (Benoit, 1997: 70-71). En efecte, el llibre havia estat traduït a Holanda el 1952; a Itàlia, Alemanya i Suïssa el 1953; a Anglaterra el 1954; i a l'espanyol el 1955 per Julio Cortázar. Igualment les jornades d'homenatge a Yourcenar i els col-loquis i congressos

\footnotetext{
${ }^{1}$ A les memòries d'Isabel García Lorca (2002) es recull la carta, datada el 10 de maig de 1960, que li va escriure Marguerite Yourcenar amb ocasió de la visita que, en companyia de Grace Frick, va fer a Víznar per visitar el lloc on el poeta havia estat assassinat.

${ }^{2}$ Les tres narracions de La mort conduit l'attelage (1933-1934), són fetes respectivament a partir de la paleta d'un pintor: «D'après Dürer», «D'après Gréco», $\mathrm{i}$ «D'après Rembrandt».

${ }^{3}$ Reagrupat a Come l'eau qui coule (1982), juntament amb «Un homme obscur» $\mathrm{i}$ «Une belle matinée».
} 
organitzats a diversos àmbits acadèmics ${ }^{4}$ són molt posteriors als anys cinquanta. Sembla fins i tot que aquesta aparent manca d'interès del públic català per l'escriptora arriba a dia d'avui: Montserrat Gallart i Sanfeliu (2008), estudiosa i traductora de Yourcenar, es queixa a les pàgines de Serra d'Or de la ressonància escassa que la commemoració del vintè aniversari de la mort de l'escriptora havia tingut a la premsa catalana — «ni explícita ni remota»—, fora d'un article de David Castillo publicat al diari Avui al desembre de 2007. Sigui com sigui, el cert és que la primera vegada que es van poder sentir les paraules de Marguerite Yourcenar en català va ser el 1972 gràcies a la iniciativa de Josep Cruz, director del mític TEI (Teatre Experimental Independent), que va posar dalt de l'escenari Electra o la caiguda de les màscares, a Girona i a la Sala Casal de Mataró. Fora, però, d'aquest experiment, del qual Serra d'Or va publicar una ressenya signada per Xavier Fàbregas (1972), les primeres traduccions al català d'obres narratives de Yourcenar daten dels anys 80 .

El primer tast el va oferir la revista Faig el 1982 amb la publicació: "Dos contes de Marguerite Yourcenar: Com fou salvat Wang-Fô [sic] (traducció d'Antònia Tayadella); i L'home que va estimar les Nereides (traducció de Manuel Espín)", ambdós procedents de Nouvelles Orientales (1938). Un any després, el 1983, va aparèixer l'edició de Memòries d'Adrià, en traducció de Jaume Creus. Tot plegat, havien passat 32 anys de la publicació de l'original i 27 des que Julio Cortázar hagués girat la novel·la al castellà, tot i que s'ha de tenir en compte que l'edició peninsular d'EDHASA no va veure la llum fins al 1982.

Potser, com suggereix Benoit, els editors no s'arriscaven "à se lancer dans l'aventure d'une traduction réservée a un públic lecteur minoritaire" (1997:71). Té sentit llavors que s'aprofités l'impuls del boom de vendes que va suposar la publicació de Memorias de Adriano, sobretot a partir de les declaracions de Felipe González, aleshores primer president socialista del Govern d'Espanya, que va posar l'obra de Yourcenar entre els seus llibres preferits (Creus, 2002; Barba, 2003). Tot i això, més aviat hem de pensar que la veritable causa del retard era la situació de llengua oprimida que el català havia viscut i vivia encara, ja que no va ser fins a la consolidació de la democràcia que la Institució de les Lletres Catalanes va poder fer una política favorable a la importació d'autors i autores estrangers a la nostra llengua. És ben sabut que la traducció d'obres cabdals de la literatura universal és un dels factors més determinants en el procés de normalització d'una llengua. A hores d'ara, a banda dels possibles ajuts institucionals que les editorials poden demanar, l'esforç i dedicació d'un bon grapat d'estudioses i traductores, juntament amb alguns traductors i estudiosos, han canviat el panorama de manera radical.

Heus aquí l'estat de la qüestió ordenat en tres apartats: $a$ ) cronologia de les traduccions de Yourcenar al català; $b$ ) referències bibliogràfiques de les obres

\footnotetext{
${ }^{4}$ Entre d'altres, el Colloque International: Marguerite Yourcenar, biographie et autobiographie, organizat pel departament de Philologie française de la Universitat de València el 1986, del qual va sorgir un dels primers centres d'estudis yourcenarians.
} 
de Marguerite Yourcenar traduïdes al català i/o al castellà; $c$ ) recepció de les traduccions catalanes de Yourcenar a la premsa de Catalunya.

\section{Cronologia de les traduccions al català}

1972 Electra o la caiguda de les màscares

1982 Dos contes de Marguerite Yourcenar: Com fou salvat Wang Fô i $L$ 'home que va estimar les Nereides.

1983 Memòries d'Adrià; i Anna, soror.

1984 Obra negra; i El temps aquest gran escultor.

1989 Contes orientals.

1990 Le tret de gràcia; Donar al Cèsar; i Amb els ulls oberts: converses amb Matthieu Galey.

1994 Alexis o el tractat del combat inútil; i El laberint del món I: Recordatoris; El laberint del món II: Arxius del Nord; El laberint del món III: Què? L'eternitat.

2005 Un home obscur i Un mati esplèndid.

2006 La moneda del somni.

2007 Focs.

2009 Alexis o el tractat del combat inútil.

2010 Conte blau. La primera nit. Malefici.

Cal afegir que, el 2001, va sortir subtitulada en català per Lluís M. Todó, la famosa entrevista que havia fet Bernard Pivot a Marguerite Yourcenar a Petite Plaisance el setembre de 1979 per al programa «Apostrophes» (07/12/1979) de la cadena francesa Antenne $2 .^{5}$

Podem distingir doncs un primer període, al llarg del qual comptem quinze traduccions, entre 1972 i 1994, any en què sembla aturar-se de cop l'interès per traduir Yourcenar. Potser aquest fet està relacionat amb el fet que la figura de l'escriptora desapareix gradualment dels medis després del seu traspàs. Al contrari, durant els anys vuitanta s'havien produït un seguit d'esdeveniments que porten Yourcenar a les primeres planes de la premsa mundial, incloent-hi la important entrevista esmentada. El 1980 fou la primera dona elegida membre de l'Académie Française - la primera, doncs, que entrà a formar part d' "Els immortels"-, l'acte de recepció a la qual amb el consegüent discurs preceptiu va tenir lloc el 22 de gener de $1981^{6}$; el 1982 és anomenada membre de l'American Academy of Arts and Letters; al mateix temps, Gallimard inclou les seves obres

\footnotetext{
${ }^{5}$ Vegeu «Els monogràfics d'Apostrophes» de la col·lecció "Videoteca de la Memòria Literària" d'Editrama (2001), feta amb l'ajut de l'Institut National de l'Audiovisuel i el Departament de Cultura de la Generalitat.

${ }^{6}$ Tanmateix Yourcenar ja era membre de l'Acadèmia belga des de 19 mars 1971. Gallimard publicà el seu Discours de réception à l'Académie royale belge de langue et de littérature françaises, i la resposta de Carlo Bronne.
} 
a La Bibliothèque de La Pléiade; el 1983 rep el premi Erasmus a Amsterdam, per posar-ne només els més significatius. Finalment, el 17 de desembre de 1987, la mort de l'escriptora - que havia continuat publicant fins llavors- alimentà arreu la convocatòria de homenatges, col-loquis i congressos.

És però a partir de 2003, any que es commemora el centenari del naixement de Yourcenar, quan sembla tornar a revifar l'interès dels editors, probablement impulsat per nous actes acadèmics, entre el quals cal esmentar l'homenatge que es va celebrar a la Universitat de Barcelona, coordinat per Mercè Otero, el 18 de desembre de 2003 (Barderi i Otero, 2004); o culturals com la jornada organitzada pel PEN Català i Montserrat Gallart a l'Ateneu Barcelonès, també al desembre del mateix any. Igualment, el 2007, amb motiu del vintè aniversari de la seva mort, se celebraren més actes commemoratius. Aquestes efemèrides i sobretot la tenacitat i l'esforç de les estudioses yourcenarianes impulsen la nova etapa de publicació de traduccions de l'escriptora. Sigui com vulgui, el cert és que, a banda de l'esmentat subtitulatge del 2001, a partir de 2005 fins a l'actualitat, constatem la publicació de gairebé una traducció cada any.

\section{Referències bibliogràfiques de les obres de Marguerite Yourcenar traduïdes al català i/o al castellà ${ }^{7}$}

\section{Alexis ou le Traité du Vain Combat (1929)}

Alexis o el tratado del inútil combate (traducción de Emma Calatayud, Madrid: Alfaguara, 1977.

Alexis o el tractat del combat inútil. Traducció de Rosa Serrano i Antònia Pallach i Estela, Barcelona: Pirene Editorial / València: Tandem Edicions, 1994.

Alexis o el tractat del combat inútil. Traducció de Montserrat Gallart, Palma: Lleonard Muntaner, 2009).

Feux (1936)

Fuegos. Traducción de Emma Calatayud, Madrid: Alfaguara, 1982.

Focs. Traducció de Montserrat Gallart i Sanfeliu, Barcelona: March, 2007.

Nouvelles Orientales (1938)

Dos contes de Marguerite Yourcenar: Com fou salvat Wnag-Fô. Traducció d'Antònia Tayadella; L'home que va estimar les Nereides. Traducció de Manuel Espín, Faig, núm. 18, p. 30-43, 1982. ${ }^{8}$

Cómo se salvó Wang-Fô. Traducción de Emma Calatayud, ilustraciones de Verónica Rubio, Madrid: Alfaguara, D. L. 1987. ${ }^{9}$

\footnotetext{
${ }^{7}$ El llistat està ordenat per ordre cronològic dels originals. Lògicament, queden excloses del llistat les obres de Yourcenar no traduïdes ni al català ni al castellà, com ara, Le Jardin des Chimères (1921), Les Dieux ne sont pas morts (1922-1923), La Nouvelle Eurydice (1931), Pindare (1932), entre d'altres.

${ }^{8}$ Es tracta d'una traducció parcial, ja que només recull dos relats dels deu que conté la col-lecció.
} 
Contes orientals. Traducció de Marina Folch, Barcelona: Empúries, 1989.

Cuentos orientales, traducción de Emma Calatayud, Madrid: Suma de Letras, 2001.

Le Coup de Grâce (1939)

El tiro de gracia. Traducción de Emma Calatayud, Madrid: Alfaguara, 1985.

Le tret de gràcia. Traducció de Maria Mercè Marçal, Barcelona: Edicions B, 1990

Mémoires d'Hadrien (Librairie Plon, 1951 / Gallimard, 1974), suivi de Carnets de notes de Mémoires d'Hadrien

Memorias de Adriano. Traducción de Julio Cortazar, Buenos Aires:

Sudamericana, 1955 / i Barcelona: EDHASA, 1982 [seguida de Cua-

dernos de notas a las «Memorias de Adriano» i «Nota», amb traducción de Marcelo Zapata].

Memòries d'Adrià. Seguit del quadern de notes de les Memòries d'Adrià. Traducció de Jaume Creus, Barcelona: Laia, DL $1983 .{ }^{10}$

Electre ou la chute des masques (1954)

Electra o la caiguda de les màscares. [Companyia: Teatre Experimental Independent. Direcció: Josep Cruz. (Traducció: Josep Cruz?). Mataró, Teatre Sala Casal. 1972, 4 de novembre].

Les Charités d'Alcippe (1956)

Las caridades de Alcipo y otros poemas. Traducción de Silvia Barón Supervielle, Madrid: Visor, 1982.

Denier du Rêve (1934, versió definitiva de 1959)

El denario del sueño. Traducción de Emma Calatayud, Madrid: Alfaguara, 1985.

La moneda del somni. Traducció de Montserrat Gallart i Sanfeliu. Barcelona: Ediciones 1984, $1^{\text {a }}$ ed. juny 2006.

L'Oeuvre au Noir (1968)

El Alquimista, Traducción de Vicente Villacampa, Barcelona: Plaza \& Janés, 1970.

Opus nigrum. Traducción de Emma Calatayud, Madrid: Alfaguara 1982.

Obra negra. Traducció de Felícia Fuster, Barcelona: Proa, «A tot vent» (C) 1984, DL 1985. Obra negra [seguit de Quadern de notes d'Obra negra] Traducció de Felícia Fuster, Traducció del Quadern de notes de Montserrat Planas, (2 ed. 1996).

\footnotetext{
${ }^{9}$ El 1986 Gallimard va fer una edició de Comment Wang-Fo fut sauvé, il-lustrada per Georges Lemoine; la versió castellana està igualment signada per la mateixa Emma Calatayud (Cómo se salvó Wang-Fô. Ilustraciones de Georges Lemoine, Madrid: Gadir, 2006).

${ }_{10}$ Altres editorials barcelonines han reeditat l'obra amb la mateixa traducció de Jaume Creus: Proa, 1990, 1996, etc.; Ediciones B: ECSA, 1999; i Edicions 62, 2007.
} 
Théatre I (Rendre à César; La petite Sirène; Le Dialogue dans le marécage) (1971)

Théatre II (Électre ou la Chute des masques; Le Mystère d'Alcestes; Qui n'a pas son Minotaure?) (1972)

Teatro (2 vols.) (1. Dar al César; La sirenita; Diálogo en la marisma /

2. Electra o La caída de las máscaras; El misterio de Alcestes; ¿Quién no tiene su minotauro?). Traducción de Silvia Barón Supervielle, Barcelona: Lumen, «Palabra en el Tiempo» 156-157), 1984.

Donar al Cèsar. Traducció de Lluís-Anton Baulenas, Barcelona: Institut del Teatre, 1990; premi Josep M. de Sagarra 1989. [Es conserva el manuscrit a l'Institut del Teatre].

Qui n'a pas son Minotaure? (1972)

Qui no té el seu minotaure? [manuscrit]. Traductor: Miguel-Ángel Sánchez i Férriz. [1988]. ${ }^{11}$

[Le labyrinthe du Monde, 1974-1988]

Souvenirs Pieux (1974)

Recordatorios: El laberinto del mundo I, traducción de Emma Calatayud, Madrid: Alfaguara, 1984.

El laberint del món I: Recordatoris, traducció de Montserrat Planas, Barcelona: Proa, 1994.

Archives du Nord (1977)

Archivos del Norte: El laberinto del mundo II, traducción de Emma Calatayud, Madrid: Alfaguara, 1984.

El laberint del món II: Arxius del Nord. Traducció de Montserrat Planas, Barcelona: Proa, 1994.

Quoi? L'Éternité (1988, postum)

¿Qué? La eternidad: el laberinto del mundo III, traducción de Emma Calatayud, Madrid: Alfaguara, D.L. 1990.

El laberint del món III: Què? L'eternitat. Traducció de Montserrat Planas, Barcelona: Proa, 1994.

Sous Bénéfice d'Inventaire (1962, versió definitiva 1978)

$A$ beneficio de inventario. Traducción de Emma Calatayud, Madrid: Alfaguara, 1987.

Marguerite Yourcenar [Images animées] Nicolas Ribowski, real; Bernard Pivot, prod., intervieweur, 1 cass video (VHS), Institut national de l'audiovisuel, $1979 .^{12}$

Versió original sostitulada en català a càrrec de Lluís M. Todó, per a "Els monogràfics d'Apostrophes" de la col·lecció "Videoteca de la Memòria Literaria" d'Editrama, 2001.

\footnotetext{
${ }^{11}$ Està dipositat a l'Institut del Teatre, són 55 folis mecanografiats i relligats.

${ }^{12}$ Entrevista realitzada a Petite Plaisance, la casa de l'escriptora a l'Île des Monts Déserts als EUA el septembre 1979 .
} 
Les yeux ouverts (1980)

Con los ojos abiertos. Entrevistas con Matthieu Galey. Traducción de Elena Berni, Gedisa-Emecé, 1982).

Amb els ulls oberts: converses amb Matthieu Galey. Traducció de Marta Segarra, Barcelona: Edicions B, 1990.

Anna Soror (1981)

Anna, soror. Traducció d'Alicia Ramón i Alfred Sargatal, Barcelona: Laertes, 1983.

Ana, soror. Traducción de Manuel Pereira, Barcelona: Círculo de Lectores, DL 2000.

Mishima ou La vision du vide (1981)

Mishima o la visión del vacio. Traducción de Enrique Sordo, Seix Barral, «Biblioteca Breve», 1985.

Comme l'eau qui coule (Anna Soror, Un homme obscur, Une belle matinée) $(1982)^{13}$

Como el agua que fluye: Ana, soror... Un hombre oscuro, Una hermosa mañana. Traducción de Emma Calatayud, Madrid: Ediciones Alfaguara, 1983.

Un home obscur i Un matí esplèndid, traducció de Lídia Anoll, pròleg d'Àngels Santa, Lleida: Pagès, editors, 2005.

Le Temps, ce grand sculpteur (Gallimard, 1983))

El Temps, aquest gran escultor. Traducció d'Avel-lí Artís Gener, Barcelona: Laia, 1984.

El Tiempo, gran escultor. Traducción de Emma Calatayud, Barcelona: Círculo de Lectores, 1990.

Les Trente-trois noms de Dieu: essai d'un journal sans date et sans pronom personnel (1986)

Los Treinta y tres nombres de Dios: ensayo de un diario sin fecha y sin pronombre personal. Traducción y prólogo de Silvia Baron Supervielle, Barcelona: Reverso, 2005. ${ }^{14}$

La Voix des choses (Gallimard, 1987) textes recueillis par Marguerite Yourcenar; photographies de Jerry Wilson.

La voz de las cosas, textos recogidos e introducidos por Marguerite Yourcenar; fotografías de Jerry Wilson; traducción de Carlos Manzano; Madrid: Gadir, [2005]

\footnotetext{
${ }^{13}$ El 1985 Gallimard va publicar una variant del recull: Un homme obscur, Une belle matinée, Le cheval noir à tête blanche, però Le cheval noir à tête blanche és un conte infantil traduït al francès per Marguerite Yourcenar, per tant ha estat exclós del nostre còmput igual que la resta d'obres traduïdes per la pròpia Yourcenar.

${ }^{14}$ No he trobat traducció al català. A la Biblioteca Nacional (Madrid) existeix un enregistrament sonor d'Antoni Parera Fons, Sobre un texto de Marguerite Yourcenar, Madrid: Universal Music Spain, D. L: 2008. (CD de $69 \mathrm{~min}$. + un folleto). També està catalogada la partitura, que es va adaptar per a la "Semana de Música Religiosa" (46a . 2007. Cuenca).
} 
En pèlerin et en étranger: essais, 1989 [compilació pòstuma feta per Gallimard].

Peregrina y extranjera, traducción de Emma Calatayud, Madrid: Alfaguara, 1992.

Le tour de la prision, Gallimard, 1991.

Una vuelta por mi cárcel. Traducción de Emma Calatayud, Madrid: Alfaguara, 1993.

Conte bleu - Le premier soir-Maléfice (Gallimard, 1993) ${ }^{15}$

Cuento azul, traducción de María Fortunata Prieto-Barral, Madrid: Alfaguara, 1995.

Conte blau. La primera nit. Malefici. Traducció de Montserrat Gallart i Montse Padrosa, Palma de Mallorca: Lleonard Muntaner, «Debiaix»6, 2010.

Lettres à ses amis et quelques autres (édition établie, présentée et annotée par Michèle Sarde et Joseph Brami, avec la collaboration d'Elyane Dezon-Jones), Paris: Gallimard, cop. 1995.

Cartas a sus amigos, traducción de María Fortunata Pietro Barral, edición preparada, presentada y anotada por Michèle Sarde y Joseph Brami con la colaboración de Elyane Dezon-Jones, Madrid: Alfaguara, [cop. 2000]

En resum, comptem amb la traducció al català de:

- Dues obres de teatre (Electra i Donar al Cèsar) més una no publicada (Qui no té el seu minotaure). En castellà, en canvi, està publicat el teatre complet.

- Nou publicacions que contenen una o més narracions curtes, algunes en trasllat de diferents traductors o traductores. De fet, de les deu Nouvelles orientales, dues compten amb sengles versions (Com fou salvat Wang-Fo i L'home que va estimar les Nereides). I les tres que van anar a parar dins Comme l'eau qui coule (Anna Soror; Un homme obscur; Une belle matinée), en versions de Alícia Ramon i Alfred Sargantal: Anna, soror; i de Lídia Anoll: Un home obscur i Un mati esplèndid. Finalment, Conte bleu; Le premier soir; Maléfice, reunits postumament per Gallimard, 1993. Així mateix, en castellà estan traduïts Cuentos orientales, i Como el agua que fluye, per mà d'Emma Calatayud, però pel que fa a l'últim aplec només està traduït Cuento azul per María Fortuna Pietro Barral. És a dir que, en aquest cas, tots els relats de Yourcenar han estat girats al català, mentre que al castellà en falten dos.

\footnotetext{
15 Conte bleu (va ser iniciat pel seu pare, Michel de Crayencour, i ampliat i conclòs per l'escriptora entre 1927 i 1930. Pertany als escrits que Yourcenar havia deixat inèdits al seu despatx de Petite Plaisance); Le premier soir (La Revue de France, 1929); Maléfice (Mercure de France, 1933).
} 
- Cinc novel-les: Alexis o el tractat del combat inútil (dues versions); Memòries d'Adrià; Obra negra; El tret de gràcia; i La moneda del somni. Totes traduïdes abans al castellà.

- Un llibre de proses poètiques: Focs. Al castellà també està traslladat Las caridades de Alcipo y otros poemas. Segons el meu còmput, tampoc no han estat traduïts a cap de les dues llengües, els dos primers poemaris de Yourcenar, Le jardin des chimères i Les Dieux ne sont pas morts.

- També tenim traduïts, primer al castellà i posteriorment al català, els tres llibres de memòries. En català estan agrupats dins el mateix volum El laberint del món, girats per Montserrat Planas.

- Quant als assaigs, en català només tenim El temps, aquest gran escultor, traslladat per Avel·lí Artís-Gener, sis anys abans que la versió castellana. En canvi, en castellà, estan traduïts pràcticament tots (a excepció de Pindare), incloent-hi els reunits pòstumament per Gallimard, com ara Peregrina y extranjera o Una vuelta por mi cárcel.

- Igualment 1'epistolari autoritzat per Yourcenar, Lettres à ses amis et quelques autres, està traduït al castellà però no al català. I no ho està a cap de les dues llengües la recent edició d'Une reconstitution passionnelle: correspondance 1980-1987 Marguerite Yourcenar, Silvia Baron Supervielle (2009).

- Sí comptem amb traducció al català de Marta Segarra de la sèrie d'entrevistes amb Matthieu Galey, Amb els ulls oberts, una traducció força més ben feta que la castellana publicada a Argentina. I també amb la versió subtitulada en català de l'entrevista de Bernard Pivot, que és essencial pel coneixement de l'autora.

Tanmateix seria desitjable el trasllat al català de la biografia de Michèle Goslar, Yourcenar. Biographie: "Qu'il eût été fade d'être hereux», ja traduïda al castella per Núria Pujol i Valls, Marguerite Yourcenar: qué aburrido hubiera sido ser feliz (Barcelona: Paidós, 2002).

D'altra banda, observem que les obres de Yourcenar al català han estan traduïdes majoritariament per dones, onze en total: Antònia Tayadella (Com fou salvat Wang Fô), Alícia Ramon (amb Alferd Sargantal) (Anna, soror), Felícia Fuster (Obra negra), Marina Folch (els 10 Contes orientals), Maria-Mercè Marçal (El tret de gràcia), Marta Segarra (Amb els ulls oberts), Rosa Serra i Antònia Pallach (el primer trasllat d'Alexis), Montserrat Planas (El laberint del món, que aplega els tres llibres de memòries i el quadern de notes d'Obra negra), Lídia Anoll (Un home obscur i Un matí esplèndid), Montserrat Gallart (La moneda del somni, Focs, Alexis o el tractat del combat inútil) i amb Montse Padrosa Conte blau, La primera nit, Malefici. En total 28 traduccions, comptant els relats per separat, les novel·les, el llibre de poemes, els tres de memòries, l'assaig, un quadern de notes, i el volum d'entrevistes de Matthieu Galey. A més a més, a hores d'ara, tenim notícia que la revista Serra d'Or publicarà, en dos lliuraments al llarg de 2011, Vuit sonets juntament amb un curt assaig en 
traducció de Montserrat Gallart, qui prepara el trasllat de tres obres més: una nova versió d'Anna Soror i de les Nouvelles orientales / Narracions orientals; i la traducció de Les songes et les sorts / Els somnis i els atzars, un assaig no girat al castellà.

Pel que fa als traductors al català, en comptem vuit: Josep Cruz (Electra o la caiguda de les màscares), Manuel Espín (L’home que va estimar les Nereides), Jaume Creus (Memòries d'Adrià), Alfred Sargantal (amb Alícia Ramon) (Anna, soror), Avel-lí Artís-Gener (El temps, aquest gran escultor), Lluís-Anton Baulenas (Donar al Cèsar), Lluís M. Todó (el subtitulatge de l'entrevista de B. Pivot «Apostrophes»), i Miguel-Ángel Sánchez i Férriz, que han fet, respectivament, vuit traduccions, una per hom, tot comptant el trasllat inèdit de Qui no té el seu minotaure? La diferència és, si més no, notable, tot i que l'obra més famosa de Yourcenar hagi estat girada per un home.

En castellà passa pràcticament el mateix, tot i que nombre de traductors es molt més reduit, sis homes: Julio Cortazar (Memorias de Adriano), Marcelo Zapata (Cuaderno de notas a las «Memorias de Adriano»), Vicente Villacampa (El Alquimista), Manuel Pereira (Ana, soror), Enrique Sordo (Mishima o la visión del vacio) i Carlos Manzano (La voz de las cosas), igualment amb una traducció cadascun, contra quatre dones, que han traduit tota la resta: Elena Berni (Con los ojos abiertos), María Fortunata Pietro Barral (Cuento azul, i Cartas a sus amigos), Silvia Baron Supervielle (Las caridades de Alcipo y otros poemas, les sis obres dramàtiques aplegades a Teatro, Treinta y tres nombres de Dios: ensayo de un diari sin fecha y sin pronombre personal), i Emma Calatayud - la gran veu de Yourcenar en castellà- que signa tota la resta: Alexis o el tratado del inútil combate, Fuegos, Cuentos orientales, El tiro de gracia, El denario del sueño, Opus nigrum, Recordatorios, Archivos del Norte, ¿Qué? La eternidad, A beneficio de inventario, Como el agua que fluye (Ana, soror..., Un hombre oscuro, Una hermosa mañana), El tiempo, gran escultor, Peregrina y extranjera, i Una vuelta por mi cárcel. Catorze volums en total, on s'apleguen 42 obres entre novel·les, narracions curtes, poesia, assaigs, memòries, i textos de viatges.

Aquesta diferència a favor del nombre de traduccions al castellà no fa minvar el mèrit del nombre de trasllats al català, més encara si pensem en termes de proporcionalitat: uns sis milions de lectors potencials de català enfront dels més de quatre-cents milions -així mateix potencials- de castellà.

\section{Recepció de les traduccions catalanes a la premsa de Catalunya}

Per acabar, quant a la recepció de les traduccions catalanes a la premsa de Catalunya, presentem aquesta primera aproximació:

- Fàbregas (1972) qualifica la traducció d'Electra o la caiguda de les màscares «de molt justa i encertada, l'origen de la qual no queda assenyalada en el programa» tot i que apunta cap al mateix director. 
- Rosa M. Piñol (1983) comentant Memòries d'Adrià, és l'única que cedeix la veu al traductor. Comença fent referència a la bibliografia del poeta Jaume Creus com a traductor, i el seu descobriment de l'obra de Yourcenar. Segueix amb la gestació de l'edició de Laia, i amb l'objectiu de la versió:

He procurado que la versión tuviera un cierto tono de libro de la categoría de los de la colección de clásicos 'Bernat Metge', que he releído principalmente para la fijación de topónimos y nombres de personajes y he intentado leer todo lo que la autora cita en la obra: Plinio el Joven, Suetonio, Tácito y los epigramas de Marcial y Calímaco.

I les principals dificultats del trasllat de l'obra al català:

Creus ha tenido que superar ciertas dificultades que planteaba adaptar a la sintaxis catalana las frecuentes secuencias de frases yuxtapuestas a base de comas o puntos y coma del texto original francés y ha procurado mantenerse fiel al tipo de lenguaje que usa la autora, "muy actual pero sin eludir algunos arcaísmos"

- Joan Josep Isern (1990), de Contes orientals, destaca la dificultat de la traducció i incorpora «amb tots els honors» la versió de Marina Folch a la llista de «versions excel-lents de gran part dels títols bàsics de l'obra d'aquesta escriptora». Menciona la llista formada per "Alícia Ramon i Alfred Sargatal (Anna Soror, Laertes, 1983), Jaume Creus (Memòries d'Adrià, Laia, 1983), Avel-lí Artís-Gener (El temps aquest gran escultor, Laia, 1984), Felícia Fuster (Obra negra, Proa, 1985) i Maria Mercè Marçal (El tret de gràcia, El Mall, 1986)"

- Joan Triadú (1991) qualifica d'excel·lents: la traducció de Jaume Creus de Memòries d'Adrià, i la de Marta Segarra d'Amb els ulls oberts. Converses amb Mathieu Galey. Igualment la "versió de la mateixa qualitat de Maria-Mercè Marçal" d'El tret de gràcia; i la de Lluís-Anton Baulenas, Donar al Cèsar. I així fins a mencionar les vuit versions en català que estaven publicades aleshores.

- M. G. (1996), fent-se ressò de la reedició de Memòries d'Adrià, es limita a apuntar: "Julio Cortazar va fer una versió meravellosa en castellà, i que ara Jaume Creus ha traduït al català". Cal remarcar a més que la primera edició del trasllat de Creus data de 1983, de manera que el crític està si més no una mica despistat quan les dates.

- Ramon Pla i Arxé (1996) qualifica de "magnífica" la traducció de Felícia Fuster d'Obra negra, però no fa cap més comentari sobre el trasllat, per bé que la crítica sobre l'original és esplèndida.

- María Asunción Guardia (2001) es limita a anunciar l'edició subtitulada de l'entrevista de Bernat Pivot, però sense ni tant sols mencionar el traductor. 
- Jaume Creus i del Castillo (2002) ofereix la llista de traduccions al català des del boom de la versió castellana de Memòries d'Adrià, menciona els traductors però sense afegir comentaris ni adjectius qualificatius.

- Pau Dito Tubau (2006) saluda La moneda del somni, però no hi dedica ni una paraula a la traducció, per bé que dóna la referència del llibre amb el nom de la traductora.

- Quim Pérez (2006) tampoc no hi dedica ni una paraula a la traducció de Gallart de la mateixa novel·la.

- Jordi Galves (2006) fa també una bona síntesi de La moneda del somni, per bé que tampoc diu res de la traducció.

- Ada Castell (2007) igualment saluda l'edició en català de Focs però no diu ni una paraula sobre el trasllat o la traductora.

- David Castillo (2007), l'únic crític que commemora el vintè aniversari de la mort de l'escriptora, fa referència a les editorials que han publicat les traduccions, però no menciona cap traductor o traductora, excepció feta de Maria-Mercè Marçal.

- E. P. (2008) ni tant sols menciona el nom de la traductora de Focs, Montserrat Gallart.

- Melcior Comes (2010), comentant Alexis, fa referència a les sengles notes preliminars de la traductora i l'autora, i opina que està "perfectament traslladada al català per Montserrat Gallard [sic] —, d'una musicalitat penetrant, el-líptica i profunda, Alexis... aconsegueix fer-se inoblidable".

- Finalment, Ramon Pla i Arxé (2010), en una crítica rigorosa d'Alexis, assenyala: "La traducció de Montserrat Gallart em sembla excel·lent. La seva introducció titulada 'A manera de pretext', és només curiosa. De fet, els vincles dels personatges literaris amb la biografia dels autors focalitzen l'atenció del lector en la vida de l'autor, no en el text."

En resum, de les setze ressenyes relacionades, escandalitza comprovar que set dels crítics ni tant sols esmenten el nom i cognom de la persona que ha fet el trasllat. Vuit es limiten a esmentar-ho, i d'aquests, només alguns afeixen un adjectiu qualificatiu més o menys elogiós. Únicament una periodista, Rosa Maria Piñol, ofereix a Jaume Creus l'oportunitat de fer un anàlisi concret i objectiu de les dificultats de la traducció i de les tècniques i procediments que ha fet servir per aconseguir produir en els lectors i lectores de la versió catalana un impacte estètic equivalent.

Podríem afegir a manera de conclusió que les traduccions al català de Marguerite Yourcenar comparades amb el trasllats al castellà no són tan tardanes com pot semblar a primera vista. De fet la primera vegada que la veu de l'escriptora es va sentir a Espanya en una llengua que no fos l'original va ser a Catalunya i en català el 1972 a l'estrena d'Electra, mentre que la primera publicada en castellà per una editorial de la península no va arribar fins cinc anys després amb Alexis o el tratado del inútil combate (1977); igualment les versions catalanes s'avancen a les castellanes en el cas d'El temps, aquest gran es- 
cultor (1984) i Contes orientals (1989). D'altra part, les traduccions catalanes compten en el seu haver amb signatures de renom com ara Tísner, Felícia Fuster o Maria-Mercè Marçal, i investigadores, crítiques i traductores com Marta Segarra, Montserrat Planas o Montserrat Gallart, entre d'altres. Finalment, el ritme actual de publicació de traduccions al català ens permet pensar que el públic català podrà tenir al seu abast d'aquí a pocs anys la pràctica totalitat de les obres de l'escriptora belga. A hores d'ara, l'esforç per incorporar al cànon de la literatura catalana una autora de la talla de Marguerite Yourcenar no pot ser més que un motiu d'orgull i d'esperança.

\section{Referències bibliogràfiques}

ARAGAY, Ignasi (2008) «Joan Triadú fa memòria», Avui, dilluns, 13 d'octubre, p. 34.

BARBA, Carles (2003) «Adriano, emperador de ayer, hombre de hoy / "Memorias de Adriano" de Marguerite Yourcenar, se podrá conseguir gratis con la edición de mañana» La Vanguardia, sábado, 8 de marzo de 2003.

BARDERI, Montserrat, i OTERO, Mercè (2004) «Crònica homenatge a Marguerite Yourcenar en el centenari del seu naixement», Lectora. Revista de dones $i$ textualitat, núm. 10, p. 285-286.

BENOIT, Claude (1997) «Les traductions catalanes de M. Yourcenar», dins Literatures catalana i francesa al llarg del segle XX / Les litteratures catalane et française au XXème siècle, Barcelona: Abadia de Montserrat, p. 6979.

CASTELLS, Ada (2007) «Yourcenar i el desig d'amagar-se», Avui. Cultura, 15 de novembre.

CASTILLO, David (2007) «Amb Yourcenar i sense», Avui, dilluns, 17 de desembre.

COMES, Melcior (2010) «L'ordit d'una vida», Presència (del 19 al 25 de febrer).

CREUS i DEL CASTILLO, Jaume (2002) «Contemporary Authors in Catalan / Marguerite Yourcenar or the Death of the Humanities» Catalan Writing (1718) novembre.

DITO TUBAU, Pau (2006) «El laberint de la solitud», Avui, dimecres, 19 de juliol.

E. P. [Ester PINO] (2008) «Focs. Palimpsest», Benzina, Barcelona núm 24 (febrer), p. 76.

FÀBREGAS, Xavier (1972) «Electra o la caiguda de les máscares», Serra d'Or, «Crònica de les estrenes», 1972, II, p. 69 [837].

GALLART i SANFELIU, Montserrat (2003) «En memòria d'una sobirana», Avui, 3 de maig.

GALLART i SANFELIU, Montserrat (2008) «En memòria d'una sobirana. En el vinté aniversari de la mort de Marguerite Yourcenar», Serra d'Or, núm 583-584 (juliol-agost), p. 23 [535]-26 [538]. 
GALVES, Jordi (2006) «Yourcenar o la dignidad», La Vanguardia. Culturas. Miércoles, 4 de octubre.

GARCÍA LORCA, Isabel (2002) Recuerdos míos, Barcelona: Tusquets.

GARGUILO, René (1989) «Marguerite Yourcenar et l'Espagne», L'Ull Crític, núm. 1, 1989, p. 57-69.

GOSLAR, Michéle (2002) Yourcenar. Marguerite Yourcenar: qué aburrido hubiera sido ser feliz (Biographie: "Qu'il eût été fade d'être heureux»). Traducció castellana de Núria Pujol i Valls, Barcelona: Paidós.

GUARDIA, María Asunción (2001) «Nabokov y Yourcenar, primeros vídeos traducidos al catalán», La Vanguardia, sábado, 31 de marzo.

ISERN, Joan Josep (1990) «Yourcenar: la grandesa de la miniatura. 'Contes orientals', un llibre de lenta elaboració», Avui. Cultura, dissabte 20 de gener.

M. G. [Moisés GALINDO] (1996) «Marguerite Yourcenar. Memòries d'Adrià. Traducció de Jaume Creus. Proa. Barcelona, 1996.», El Pou de Lletres (Manresa), núm B/2 (estiu 1996), p. 28.

PÉREZ, Quim (2006) «Una peça de deu lires i una pila de somnis», Benzina. Barcelona, núm 7 (setembre), p. 70.

PIÑOL, Rosa Maria (1983) «Jaume Creus ha traducido la obra de Marguerite Yourcenar / Aparece la edición catalana de la obra "Memorias de Adriano"», La Vanguardia, martes 6 de diciembre.

PLA i ARXÉ, Ramon (1996) «Passió freda», Avui, dijous, 12 de setembre.

PLA i ARXÉ, Ramon (2010) «Inútil combat», El Temps, núm 1353 (18 de maig), p. 87.

TRIADU, Joan (1991) «Fer literatura de la vida i vida de la literatura», Avui. Cultura, dissabte 2 de març 